\title{
Achieving the Goals of Healthy China 2030 Depends on Increasing Smoking Cessation in China: Comparative Findings from the ITC Project in China, Japan, and the Republic of Korea
}

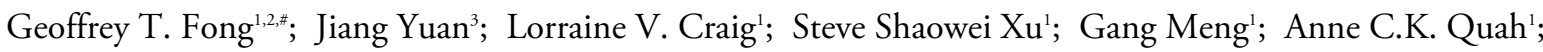 \\ Hong-Gwan Seo ${ }^{4}$; Sungkyu Lee'; Itsuro Yoshimi ${ }^{6}$; Kota Katanoda ${ }^{6}$; Takahiro Tabuchi ${ }^{7}$
}

\section{Summary}

Tobacco smoking is the number one preventable cause of disease and death in China as it is globally. Indeed, the toll of smoking in China is much greater than its status as the world's most populous country. There is a persistent and continuing need for China to implement the measures specified in the global tobacco control treaty, the World Health Organization (WHO) Framework Convention on Tobacco Control (FCTC), which China ratified in 2005. The theme for the 2021 WHO World No Tobacco Day focuses on the need to support smoking cessation. This article presents findings from the International Tobacco Control (ITC) Policy Evaluation Project cohort surveys in China, in comparison to ITC cohort surveys in two neighboring countries: Japan and the Republic of Korea. These findings demonstrate that smokers in China very much want to quit, but these intentions are not being translated into quit attempts, relative to smokers in Japan and the Republic of Korea. Additionally, about $80 \%$ of Chinese smokers want the Chinese government to do more to control smoking. These findings reaffirm the need for China to implement strong, evidencebased measures to reduce smoking. The objective of Healthy China 2030 to reduce deaths from noncommunicable diseases by $30 \%$ can be achieved by reducing smoking prevalence from its current $26.6 \%$ to $20 \%$, and this reduction can be achieved through strong implementation of FCTC measures.

The devastation caused by smoking in China is monumental. According to the Global Burden of Disease Study (1), in 2017, smoking caused 2.2 million deaths among smokers and an additional 0.4 million deaths among non-smokers due to secondhand smoke, with the total of 2.6 million deaths establishing smoking as the leading cause of death in China. The magnitude of the death and disease caused by smoking in China far exceeds China's position as the most populated country in the world: although China represents $18.5 \%$ of the global population, it suffers one-third of annual global deaths from smoking (7.1 million) and secondhand smoke (1.2 million) (2). The economic cost of smoking is also extraordinary, estimated to be as high as 368 billion CNY (3).

The goal of Healthy China 2030 is to reduce noncommunicable diseases (NCD) deaths by 30\%. But this cannot be achieved without great reductions in smoking. China has taken the critically important step of incorporating tobacco control into the Healthy China 2030 plan, but it is important to take strong action to achieve these dramatic reductions in smoking. Fully implementing the key demand reduction measures of the World Health Organization (WHO) Framework Convention on Tobacco Control (FCTC) - higher taxes; comprehensive national smoke-free laws; large pictorial warnings on cigarette packs; strongly enforced comprehensive bans on tobacco advertising, promotion, and sponsorship; and support for cessation (demand-reduction strategies that correspond to the WHO's MPOWER* measures) (4) - is strongly associated with reductions in smoking prevalence (5). It is estimated that if China were to achieve this full implementation, smoking prevalence would decrease from $26.6 \%$ in 2018 (G) to $20 \%$, and this would lead to the achievement of the Healthy China 2030 goal ( 7 ).

The theme for the 2021 WHO World No Tobacco Day is "Commit to Quit", which is a year-long campaign launched in December 2020 designed to promote smoking cessation (8) — a key component of the FCTC. The FCTC obligates 181 countries, including China, to implement strong tobacco control

\footnotetext{
* MPOWER: Monitor tobacco use and prevention policies; Protect people from tobacco smoke; Offer help to quit tobacco use; Warn about the dangers of tobacco; Enforce bans on tobacco advertising, promotion and sponsorship; Raise taxes on tobacco.
} 
measures to promote cessation and to prevent tobacco uptake. Article 14 of the FCTC focuses on measures to encourage cessation and treatment for tobacco dependence. Reviews have found that Article 14 implementation has been poor (9-10). In 2018, only 23 countries had implemented comprehensive cessation services (11), which include implementing effective cessation programs, including diagnosis and treatment of tobacco dependence in health care settings, involving medical and health care professionals, and in taking steps to make evidencebased cessation treatments (e.g., stop smoking medications) available and affordable.

\section{INDICATORS OF CHINA'S PROGRESS IN ARTICLE 14 IMPLEMENTATION}

The International Tobacco Control (ITC) Policy Evaluation Project examined indicators of progress on cessation in China in comparison with two other ITC East Asian countries - the Republic of Korea and Japan - based on data from the most recent ITC cohort surveys of smokers [China (2013-2015); Republic of Korea and Japan (2020)]. Extensive information about the methods of the ITC cohort surveys are available elsewhere (12-15). Briefly, the ITC China Survey was conducted among 7,817 adult smokers selected using a multistage probability sample in 10 locations in China: 5 cities (Beijing, Shanghai, Guangzhou, Kunming, Shenyang) and 5 rural areas (Changzhi, Huzhou, Tongren, Xining, Yichun). The Republic of Korea web-administered cohort survey was conducted among 3,766 adult smokers from a national survey panel. The Japan web-administered cohort

TABLE 1. Smoking prevalence in China, Japan, and the Republic of Korea over time.

\begin{tabular}{cccc}
\hline Country & $\mathbf{2 0 1 0}$ & $\mathbf{2 0 1 5}$ & $\mathbf{2 0 1 8}$ \\
\hline China & $28.1 \%$ & $27.7 \%$ & $26.6 \%$ \\
Japan & $19.5 \%$ & $18.2 \%$ & $17.8 \%$ \\
The Republic of Korea & $27.5 \%$ & $22.6 \%$ & $22.4 \%$
\end{tabular}

Note: Smoking prevalences in China are from the 2010 and 2018 Global Adult Tobacco Survey $(6,16)$ and from the 2015 China Adults Tobacco Survey (17). Smoking prevalences in Japan are from the National Health and Nutrition Survey (NHNS) Japan (18). Smoking prevalences in the Republic of Korea are from the Republic of Korea National Health and Nutrition Examination Survey (KNHANES) (19).

* The smoking prevalence in Japan for 2018 may also include users of heated tobacco products (HTPs), since the NHNS asked about "smoking", thus not making a clear distinction between cigarettes and HTPs. survey was conducted among 2,757 adult smokers from a national survey panel. Table 1 presents the smoking prevalence of the three countries over time.

\section{INTENTIONS TO QUIT AND QUIT ATTEMPTS}

ITC cohort surveys asked smokers if they are planning to quit smoking, and if so, their timeframe (next month, next six months, beyond six months). Intentions to quit is a strong predictor of future quit attempts and success. In China, for example, smokers reporting having plans to quit smoking were much more likely than smokers having no plans to quit to report 18 months later that they had attempted to quit $(41 \%$ vs. $17 \%)(20)$.

Figure 1 presents the percentage of smokers who intend to quit within the next six months at the most recent ITC cohort survey wave in China, Japan, and the Republic of Korea. The majority of Chinese smokers do not have intentions to quit smoking in the near future. However, a higher percentage of smokers in China (28\%) and the Republic of Korea (31\%) plan to quit in the next six months compared to only $11 \%$ of smokers in Japan.

Smokers were also asked about their previous quit attempts. The majority of Chinese smokers reported that they made no attempts to quit smoking in the last year. Approximately 1 in 5 Chinese smokers made attempts to quit (19\%), compared to approximately half of smokers in the Republic of Korea (50\%) and Japan (54\%) (Figure 1).

The gap between intentions to quit and actual quit attempts is striking in China versus its two neighboring countries. Chinese smokers intend to quit at nearly the same proportion (28\%) as Korean smokers (31\%), both much higher than Japanese smokers $(11 \%)$. But Chinese smokers are much less likely to actually attempt to quit (19\%) compared to Japanese smokers $(54 \%)$ and Korean smokers (50\%). This suggests that Chinese smokers recognize the importance of quitting and want to quit, but these intentions are much less likely to be translated into action. This suggests the importance in China of encouraging and supporting smokers to quit, which is precisely the objective of FCTC Article 14.

\section{PHYSICIAN ADVICE TO QUIT}

Physicians and other health professionals are an 


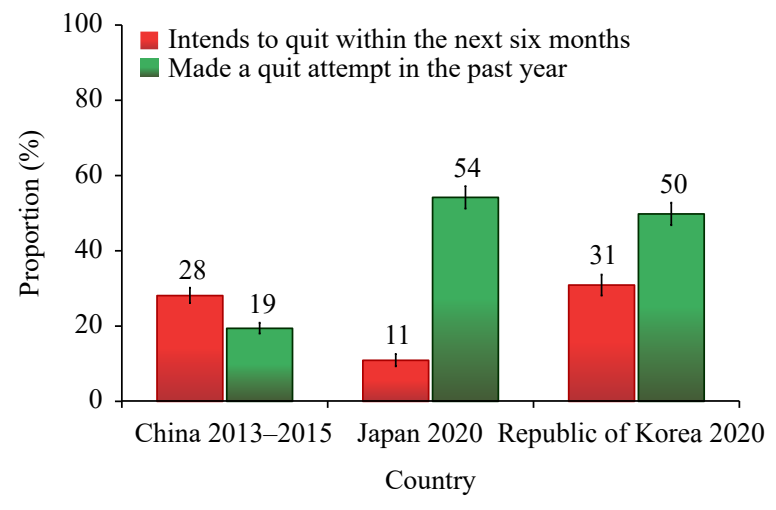

FIGURE 1. Percentage of smokers who intend to quit in the next six months and who made a quit attempt in the past year, by country.

important source of information and motivation for smokers to quit: even very brief advice from physicians can lead to a 1 to 3 percentage point increase in cessation rates (21). ITC Surveys asked smokers whether they had visited a physician or other health professional in the last six months and if they received advice to quit smoking during any visit. In China, $56 \%$ of smokers who visited a physician or health professional received advice to quit compared to $74 \%$ in the Republic of Korea, both significantly higher than $22 \%$ of smokers in Japan. In China, there is tremendous room for improvement since $44 \%$ of Chinese smokers did NOT receive critically important quit advice from their physician/health professional. This is an even greater need in Japan, where over threequarters of smokers received no such advice.

\section{SUPPORT FOR STRONGER GOVERNMENT ACTION ON TOBACCO}

Figure 2 shows that Chinese smokers were more likely to agree that the government should do more to control smoking $(80 \%)$, compared to $60 \%$ of Korean smokers and $25 \%$ of Japanese smokers. Chinese smokers were also much more likely to support a total ban if they received government support to quit (83\%) than Korean smokers (42\%) and Japanese smokers $(29 \%)$.

\section{CONCLUSION}

These findings demonstrate that smokers in China very much want to quit, and they support stronger action of the government to help them quit, compared

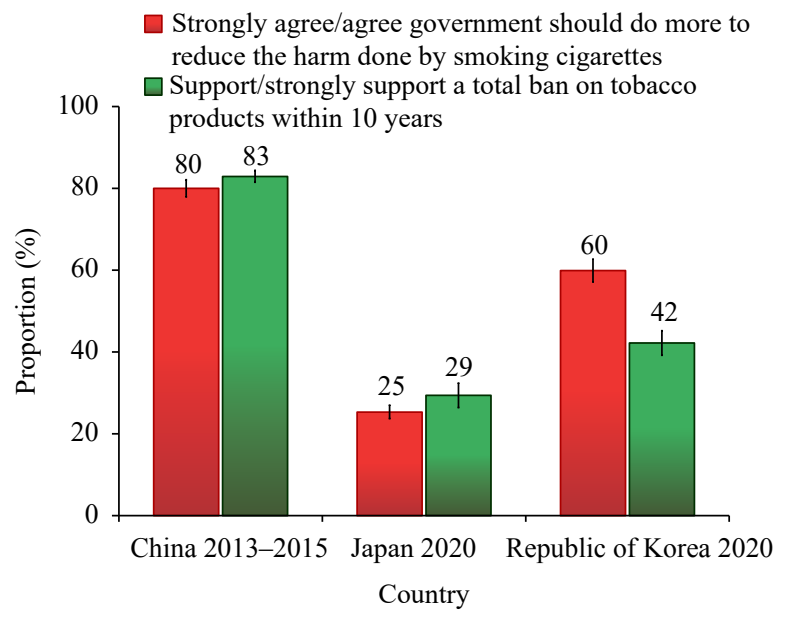

FIGURE 2. Percentage of smokers who support more government action to reduce the harm of cigarettes and who support a total ban on tobacco products within 10 years.

to smokers in the Republic of Korea and Japan. For World No Tobacco Day in 2021, WHO calls on governments to ensure that their citizens have access to brief advice, toll-free quit lines, mobile and digital cessation services, nicotine replacement therapies, and other supports for quitting.

It should be noted, as a limitation, that this study compared data collected in China in 2013-2015 with data collected in 2020 in Japan and the Republic of Korea. Tobacco control efforts at the city level have been reported to improve in China since that time, but that would likely have only increased the level of support among smokers for stronger tobacco control action, thus making any claims that the Chinese people would not support stronger policies even less valid.

China's smoking pandemic has likely not yet peaked in its devastation since the consequences of smoking are experienced in disease and death at a lag of many years (22). China has recognized the dire future consequences of smoking and has, in its Healthy China 2030 Plan, committed to reduce its smoking prevalence from $26.6 \%$ in 2018 to below $20 \%$ in 2030. This study's findings demonstrate that it is important for the Chinese government to strengthen and accelerate actions to achieve this objective and to implement Article 14 as well as other important measures that have been proven to be effective including large pictorial health warnings (Article 11), price and tax increases (Article 6), a comprehensive smoke-free law (Article 8), education campaigns (Article 12) and bans on tobacco advertising and promotion (Article 13). 
Despite the clear need for China to implement strong FCTC policies from analyses suggesting that implementing those policies would lead to substantial declines in smoking prevalence (5) at levels that would achieve the Healthy China 2030 objective (7), and despite the fact that Chinese smokers themselves would support strong implementation, there has been insufficient progress in tobacco control in China. Although there are widespread cultural practices, for example, sharing or gifting cigarettes, that help to sustain and normalize smoking (23-24), the tobacco industry's influence is the most important barrier to stronger tobacco control in China (25), as it is in Japan (26), and globally, especially in low- and middleincome countries (27). Once again, China is at the crossroads (28).

Acknowledgement: Eunice Ofeibea Indome, Ph.D., of the ITC Project, University of Waterloo.

Statement of Interests: Geoffrey T. Fong has been an expert witness or consultant on behalf of governments in litigation involving the tobacco industry. All other authors have no conflicts of interests to declare.

Funding: The ITC 2013-2015 China Wave 5 Survey was supported by grants from the Canadian Institutes of Health Research (MOP-115016), and the Chinese Center for Disease Control and Prevention. The 2020 ITC Republic of Korea Wave 1 Survey was supported by a grant from the Republic of Korea National Health Promotion Fund and the Canadian Institutes of Health Research Foundation Grant (FDN-148477). The 2020 ITC Japan Wave 3 Survey was supported by the Canadian Institutes of Health Research Foundation Grant (FDN-148477). Additional support to GTF, LVC, SSX, GM, and ACKQ was provided by the Canadian Institutes of Health Research Foundation Grant (FDN-148477). GTF is also supported by a Senior Investigator Grant from the Ontario Institute for Cancer Research and the Canadian Cancer Society 2020 O. Harold Warwick Prize.

doi: $10.46234 / \mathrm{ccdcw} 2021.120$

\# Corresponding author: Geoffrey T. Fong, gfong@uwaterloo.ca.

\footnotetext{
${ }^{1}$ University of Waterloo, Waterloo, Ontario, Canada; ${ }^{2}$ Ontario Institute for Cancer Research, Toronto, Ontario, Canada; ${ }^{3}$ Tobacco Control Office, China CDC, Beijing, China; ${ }^{4}$ Korea National Cancer Center, Seoul, Republic of Korea; ${ }^{5}$ Korea Center for Tobacco Research and Education, Seoul, Republic of Korea; ${ }^{6}$ Japan National Cancer Center, Tokyo, Japan; ${ }^{7}$ Osaka International Cancer Institute, Osaka, Japan.
}

Submitted: May 10, 2021; Accepted: May 22, 2021

\section{REFERENCES}

1. Zhou MG, Wang HD, Zeng XY, Yin P, Zhu J, Chen WQ, et al. Mortality, morbidity, and risk factors in China and its provinces, 19902017: a systematic analysis for the Global Burden of Disease Study 2017. Lancet 2019;394(10204):1145 - 58. http://dx.doi.org/10.1016/ S0140-6736(19)30427-1.

2. GBD 2017 Risk Factor Collaborators. Global, regional, and national comparative risk assessment of 84 behavioural, environmental and occupational, and metabolic risks or clusters of risks for 195 countries and territories, 1990-2017: a systematic analysis for the Global Burden of Disease Study 2017. Lancet 2018;392(10159):1923 - 94. http://dx. doi.org/10.1016/S0140-6736(18)32225-6.

3. Shi LL, Zhong LM, Cai YY. Economic burden of smoking-attributable diseases in China: a systematic review. Tob Induc Dis 2020;18:42. http://dx.doi.org/10.18332/tid/120102.

4. World Health Organization (TFI). MPOWER brochures and other resources. https://www.who.int/tobacco/mpower/publications/en/. [2021-03-11].

5. Gravely S, Giovino GA, Craig L, Commar A, D'Espaignet ET, Schotte $\mathrm{K}$, et al. Implementation of key demand-reduction measures of the WHO Framework Convention on Tobacco Control and change in smoking prevalence in 126 countries: an association study. Lancet Public Health 2017;2(4):e166 - 74. http://dx.doi.org/10.1016/S24682667(17)30045-2.

6. China Center for Disease Control and Prevention, World Health Organization, Centers for Disease Control and Prevention. Global adult tobacco survey fact sheet China 2018. https:/www.who.int/docs/ default-source/wpro---documents/countries/china/2018-gats-chinafactsheet-cn-en.pdf. [2019-5-23]. (In Chinese).

7. Fong GT. The impact of implementation of the WHO framework convention on tobacco control (FCTC) on tobacco use and public health. https://itcproject.org/findings/fact-sheets/nov-18-2019-theimpact-of-implementation-of-the-who-framework-convention-ontobacco-control-fctc-on-tobacco-use-and-public-health/. [2021-05-28]

8. World Health Organization. WHO launches year-long campaign to help 100 million people quit tobacco. News Release. 2020 December 8. https://www.who.int/news/item/08-12-2020-who-launches-year-longcampaign-to-help-100-million-people-quit-tobacco. [2021-03-08].

9. Chung-Hall J, Craig L, Gravely S, Sansone N, Fong GT. Impact of the WHO FCTC over the first decade: a global evidence review prepared for the Impact Assessment Expert Group. Tob Control 2019;28 (S2):S119 - 28. http://dx.doi.org/10.1136/tobaccocontrol-2018-054389.

10. Nilan K, Raw M, McKeever TM, Murray RL, McNeill A. Progress in implementation of WHO FCTC Article 14 and its guidelines: a survey of tobacco dependence treatment provision in 142 countries. Addiction 2017;112(11):2023 - 31. http://dx.doi.org/10.1111/add.13903.

11. World Health Organization. WHO report on the global tobacco epidemic 2019. Geneva: World Health Organization; 2019. CC BYNC-SA 3.0 IGO licence. https://apps.who.int/tobacco/global_report/ en/.

12. Wu CB, Thompson ME, Fong GT, Li Q, Jiang Y, Yang Y, et al. Methods of the International Tobacco Control (ITC) China survey. Tob Control 2010;19(S2):i1 - 5. http://dx.doi.org/10.1136/tc.2009. 029900 .

13. International Tobacco Control Project. ITC China Wave 5 (2013-2015technicateporthttps://itcproject.s3.amazonaws.com/uploads/ documents/ITC_China_Wave_5_Tech_Report_April_5_2017_F.pdf. [2017-11-11]

14. International Tobacco Control Project. ITC Japan Wave 3 technical report. https://itcproject.s3.amazonaws.com/uploads/documents/ITC_ JP3_Technical_Report-8December2020.pdf. [2020-12-1].

15. International Tobacco Control Project. ITC Korea Wave 1 (Third Cohort) technical report. https://itcproject.s3.amazonaws.com/uploads/ documents/ITC_KRA1_Technical_Report-March2021.pdf. [2021-03$11]$.

16. China Center for Disease Control and Prevention, World Health 
Organization, Centers for Disease Control and Prevention. Global adult tobacco survey fact sheet China: 2010. https://www.who.int/tobacco/ surveillance/en_tfi_china_gats_factsheet_2010.pdf. [2010-08-12].

17. Chinese Center for Disease Control and Prevention. 2015 Chinese adults tobacco survey report. 2015. http://www.notc.org.cn/gzdt/ 201512/t20151228_123959.html. [2015-12-28]. (In Chinese).

18. Japan Ministry of Health, Labor and Welfare. The National Health and Nutrition Survey (NHNS) Japan, 2018 summary. https://www. nibiohn.go.jp/eiken/kenkounippon21/download_files/eiyouchousa/201 8.pdf. [2021-05-01]

19. Kim Y. The Korea National Health and Nutrition Examination Survey (KNHANES): current status and challenges. Epidemiol Health 2014;36:e2014002. http://dx.doi.org/10.4178/epih/e2014002.

20. Li L, Feng GZ, Jiang Y, Yong HH, Borland R, Fong GT. Prospective predictors of quitting behaviours among adult smokers in six cities in China: findings from the International Tobacco Control (ITC) China survey. Addiction 2011;106(7):1335 - 45. http://dx.doi.org/10.1111/ j.1360-0443.2011.03444.x.

21. Stead LF, Buitrago D, Preciado N, Sanchez G, Hartmann-Boyce J, Lancaster T. Physician advice for smoking cessation. Cochrane Database Syst Rev 2013;2013(5):CD000165. http://dx.doi.org/10.1002/ 14651858.CD000165.pub4.

22. Lopez AD, Collishaw NE, Piha T. A descriptive model of the cigarette epidemic in developed countries. Tob Control 1994;3(3):242-7.
https://www.ncbi.nlm.nih.gov/pmc/articles/PMC1759359/.

23. Ding D, Hovell MF. Cigarettes, social reinforcement, and culture: a commentary on "Tobacco as a social currency: cigarette gifting and sharing in China". Nicotine Tob Res 2012;14(3):255-7. http://dx.doi.org/10.1093/ntr/ntr277.

24. Rich ZC, Xiao SY. Tobacco as a social currency: cigarette gifting and sharing in China. Nicotine Tob Res 2012;14(3):258 - 63. http://dx. doi.org/10.1093/ntr/ntr156.

25. Yang GH, Wang Y, Wu YQ, Yang J, Wan X. The road to effective tobacco control in China. Lancet 2015;385(9972):1019-28. http://dx.doi.org/10.1016/S0140-6736(15)60174-X.

26. Iida K, Proctor RN. Learning from Philip Morris: Japan Tobacco's strategies regarding evidence of tobacco health harms as revealed in internal documents from the American tobacco industry. Lancet 2004;363(9423):1820 - 4. http://dx.doi.org/10.1016/S0140-6736(04) 16310-1.

27. Lee S, Ling PM, Glantz SA. The vector of the tobacco epidemic tobacco industry practices in low and middle-income countries. Cancer Causes Control 2012;23(1):117 - 29. http://dx.doi.org/10.1007/ s10552-012-9914-0.

28. Fong GT, Jiang Y. The importance of reducing smoking in China: to achieve Healthy China 2030 while reducing the severity of the COVID-19 pandemic. China CDC Wkly 2020;2(2):404-6. http://dx.doi.org/10.46234/ccdcw2020.103. 